\title{
Effect of the Evaporative Cooling on the Human Thermal Comfort and Heat Stress in a Greenhouse under Arid Conditions
}

\author{
A. M. Abdel-Ghany, ${ }^{1,2}$ I. M. Al-Helal, ${ }^{1}$ and M. R. Shady ${ }^{1}$ \\ ${ }^{1}$ Department of Agricultural Engineering, College of Food and Agriculture Sciences, King Saud University, \\ P.O. Box 2460, Riyadh 11451, Saudi Arabia \\ ${ }^{2}$ Mechanical Power Engineering Department, Faculty of Energy Engineering, Aswan University, Aswan 81528, Egypt \\ Correspondence should be addressed to A. M. Abdel-Ghany; aghany@ksu.edu.sa
}

Received 7 March 2013; Revised 24 August 2013; Accepted 30 August 2013

Academic Editor: Harry D. Kambezidis

Copyright (c) 2013 A. M. Abdel-Ghany et al. This is an open access article distributed under the Creative Commons Attribution License, which permits unrestricted use, distribution, and reproduction in any medium, provided the original work is properly cited.

Thermal sensation and heat stress were evaluated in a plastic greenhouse, with and without evaporative cooling, under arid climatic conditions in Riyadh, Saudi Arabia. Suitable thermal comfort and heat stress scales were selected for the evaluation. Experiments were conducted in hot sunny days to measure the required parameters (i.e., the dry and wet bulb temperatures, globe temperature, natural wet bulb temperature, and solar radiation flux) in the greenhouse. The results showed that in the uncooled greenhouse, workers are exposed to strong heat stress and would feel very hot most of the day time; they are safe from heat stress risk and would feel comfortable during night. An efficient evaporative cooling is necessary during the day to reduce heat stress and to improve the comfort conditions and is not necessary at night. In the cooled greenhouse, workers can do any activity: except at around noon they should follow a proposed working schedule, in which the different types of work were scheduled along the daytimes based on the heat stress value. To avoid heat stress and to provide comfort conditions in the greenhouses, the optimum ranges of relative humidity and air temperature are $48-55 \%$ and $24-28^{\circ} \mathrm{C}$, respectively.

\section{Introduction}

1.1. Background. Human thermal comfort is defined as a condition of mind, which expresses satisfaction with the surrounding environment. In the arid regions, evaporative cooling is often applied to reduce the inside greenhouse air temperature in summer. Greenhouse environment is usually designed according to the crop growth requirements $\left(T_{d}: 20-\right.$ $30^{\circ} \mathrm{C}$; RH: 70-80\%) which, in many situations, may not be suitable for humans that are working in the greenhouse [1]. This is mainly because relative humidity in the evaporativelycooled greenhouses is much higher than outside. High air humidity may provide discomfort sensations and heat stress in the greenhouse. On the other hand, evaporative cooling and air stream can improve the comfort conditions in the greenhouses in hot summer [2]. Discomfort and heat stress reduce productivity of the greenhouse workers and may lead to more serious health problems, especially for aged workers [2]. Therefore, greenhouse workers should take care when they enter the greenhouse in hot summer to protect their health from heat and/or sunstroke [1]. Factors affecting human thermal comfort and heat stress level can be classified according to [3] as (i) environmental factors such as the dry bulb temperature of air and its relative humidity $\left(T_{d}\right.$ and $\mathrm{RH})$, air current speed, and the mean radiant temperature of the surrounding $\left(T_{\mathrm{mrt}}\right)$; (ii) Physiological factors such as the body metabolic heat generation rate $(M$ in met, $1 \mathrm{met}=58.15 \mathrm{~W} \mathrm{~m}^{-2}$ ) which depends on different factors such as personal activity, gender, age, nationality, and type of clothing. Thermal scales for determining human mean sensation to the environment and heat stress were developed based on human body energy balance under comfort conditions, in which, the rate of energy generated by a human's body $(M)$ should equal the rate of energy needed for the external mechanical work $(W)$ plus the rate of energy released from the body through respiration, evaporation, convection, and radiation. Therefore, a person should lose heat at a rate of $(M-W)$ in order to be comfortable. Heat exchange 
between the clothing surface of the body and surrounding is by radiation, convection, evaporation due to sweating, skin diffusion, respiratory evaporative heat, and respiratory convective heat loss.

Human thermal comfort and heat stress in the indoor and outdoor have been discussed exhaustively in several studies such as [4-15]. Most of these studies focused on the environmental conditions for human occupancy to evaluate the human thermal comfort and heat stress potential. However, in greenhouses, the wet bulb globe temperature (WBGT) was measured under mild climatic conditions [1, $2]$. Both $[1,2]$ considered the WBGT as an indication of human thermal comfort. However, the comfort condition of workers is usually measured by the comfort scales not by the WBGT which is a scale of heat stress. These studies concluded that the workers should take care to enter the greenhouses at around noon to avoid the heat stress risks. In fact the greenhouse environment should be evaluated by heat stress levels together with the thermal sensation of workers.

1.2. Heat Stress and Thermal Comfort Scales. The WBGT $\left({ }^{\circ} \mathrm{C}\right)$ can be calculated in the greenhouse using a correlation proposed by ISO-7234 standard for the outdoor conditions (in the presence of solar radiation) and is given by $[3,16]$ as

$$
\mathrm{WBGT}=0.7\left(T_{\mathrm{nw}}\right)+0.2\left(T_{g}\right)+0.1\left(T_{d}\right),
$$

where $T_{\text {nw }}\left({ }^{\circ} \mathrm{C}\right)$ is the natural wet bulb temperature (i.e., commonly measured with a thermometer that is covered with a moist, white muslin wick and exposed to the atmosphere without ventilation or shading); $T_{g}\left({ }^{\circ} \mathrm{C}\right)$ is the globe temperature (i.e., commonly measured with a temperature probe placed in the center of a blackened, hollow copper sphere). Both $T_{\mathrm{nw}}$ and $T_{g}$ are passively exposed to the ambient environment. To provide a schedule useful for greenhouse workers, a classification of different types of activities in the greenhouse according to the highest permissible value of the WBGT was adapted from $[2,16,17]$ and illustrated in Table 1.

Besides the WBGT, the temperature-humidity index (THI) is sometime used for evaluating heat stress and the predictive mean vote (PMV) is used for human thermal comfort [3]. However, the THI cannot precisely describe the heat stress in arid environment [18]. Moreover, the range of the PMV scale is limited (i.e., from -3 representing very cold to +3 representing very hot) [3]; it can not be applied for a greenhouse without cooling under arid conditions $\left(T_{d}>\right.$ $\left.45^{\circ} \mathrm{C}, \mathrm{RH}<15 \%\right)$. PMV may be useful for cooled greenhouses. However, under extreme arid conditions, universal scales are needed to be used for evaluating the human thermal sensation and heat stresses. The suitable scales to be applied in the arid environment could be summarized in the following.

(1) The physiological effective temperature (PET) and the universal thermal climatic index (UTCI) are used for evaluating thermal comfort and heat stress as well; both are in temperature scale. PET gives an estimation of the thermal sensation and the corresponding heat stress. PET is based on the Munich EnergyBalance Model for Individuals (MEMI) and a twonode model, not being constrained by a steady state
TABLE 1: Various types of greenhouse work and the corresponding highest permissible WBGT values.

\begin{tabular}{lcc}
\hline Type of greenhouse work & $M$ (met) & $\begin{array}{c}\text { Permissible } \\
\text { WBGT }\left({ }^{\circ} \mathrm{C}\right)\end{array}$ \\
\hline $\begin{array}{l}\text { No work is recommended } \\
\text { Preparation of spinach, defoliation } \\
\text { of strawberry, leaves swing, } \\
\text { standing relaxed, and so forth }\end{array}$ & $0.7-1$ & $>32.5$ \\
$\begin{array}{l}\text { Disbudding, training, pinching, } \\
\text { planting, chemical spraying, and so } \\
\text { forth }\end{array}$ & $1-2$ & $<32.5$ \\
$\begin{array}{l}\text { Weeding, fruit thinning, fertilizing, } \\
\text { standing poles, extending screens, } \\
\text { and so forth }\end{array}$ & $2-3$ & $<29.0$ \\
$\begin{array}{l}\text { Mowing, preparation of nursery } \\
\text { beds, and so forth }\end{array}$ & $3-4$ & $<27.5$ \\
$\begin{array}{l}\text { Soil mounding, row creation, } \\
\text { removal of crop wastes, and so forth } \\
\text { Digging with a spade, working with } \\
\text { an axe, and so forth }\end{array}$ & $4-5$ & $<26.5$ \\
\hline
\end{tabular}

approach; PET is applicable for both the indoor and outdoor environment studies [14]. Several advantages of using PET as reported by [14] include that (i) it is a universal index; clothing (clo values) and metabolic activity (met values) do not lead to significantly different PET values; (ii) it gives the real effect of the sensation of climate by human beings; (iii) it is measured in ${ }^{\circ} \mathrm{C}$ and so can be easily related to common experience; and (iv) it is useful in both hot and cold climates so it can be applied successfully in the arid environment. In the greenhouses, PET can be calculated simply by RayMan software (i.e., freely available by its authors). RayMan model takes simple inputs, that is, the air dry bulb temperature $\left(T_{d}\right)$, relative humidity $(\mathrm{RH})$, wind velocity, and either mean radiant temperature $\left(T_{\text {mrt }}\right)$ or the transmitted global solar radiation flux $\left(S_{i}\right)$ [19]. In addition, value of $T_{\mathrm{mrt}}$ can be calculated using theoretical models reported in [15]. RayMan model is valid for hot and sunny climate in which, values of $T_{\mathrm{mrt}}$ exceed $60^{\circ} \mathrm{C}$ at around noon. Ranges of PET for different grades of thermal perception by human beings are reported in [20].

(2) The UTCI was developed for characterizing thermal stress. It is an equivalent temperature for a given combination of wind, radiation, humidity and air dry bulb temperature. The associated assessment scale for the UTCI was developed from the simulated physiological responses and comprises 10 categories that range from extreme cold stress to extreme hot stress [21]. The UTCI was designed for wide ranges of activities, clothing resistance, and climatic conditions. UTCI can be calculated simply by using the UTCI calculator, which is made freely available by its authors on the website [22]. The input parameters to this calculator are $T_{d}, \mathrm{RH}$, and the temperature difference $\Delta T\left(\Delta T=T_{\mathrm{mrt}}-T_{d}\right)$. 
(3) The standard effective temperature $\left(\mathrm{SET}^{*}\right)$ index describes the relationship between thermal sensation (TSENS) and discomfort (DISC). SET ${ }^{*}$ is the most appropriate way for comparing thermal sensation, discomfort and physiological effect of a wide range of environmental situations, clothing, and activity levels under extreme weather conditions [23]. The SET ${ }^{*}$ and $T_{\mathrm{mrt}}$ in the greenhouses can be calculated using RayMan software model if the transmitted global solar radiation flux $\left(S_{i}\right)$ is available as an input parameter.

Workers in the greenhouse are exposed to heating load that depends mainly on the difference between the surface temperature of clothing $\left(T_{\mathrm{cl}}\right)$ and the mean radiant temperature $\left(T_{\mathrm{mrt}}\right)$. Value of the $T_{\mathrm{cl}}$ is affected by the body and the surrounding conditions, and it is impossible to be measured directly. Therefore, value of $T_{\mathrm{cl}}$ is usually computed iteratively according to $[3,9]$ using the following equation:

$$
\begin{aligned}
T_{\mathrm{cl}}= & 35.7-0.028(M-W)-3.69 \times 10^{-8} I_{\mathrm{cl}} F_{\mathrm{cl}} \\
& \times\left[\left(T_{\mathrm{cl}}+273\right)^{4}-\left(T_{\mathrm{mrt}}+273\right)^{4}\right]-I_{\mathrm{cl}} F_{\mathrm{cl}} h_{\mathrm{c}}\left(T_{\mathrm{cl}}-T_{d}\right),
\end{aligned}
$$

where $I_{\mathrm{cl}}$ is the insulation resistance of the entire clothing (e.g., $I_{\mathrm{cl}}=0.11^{\circ} \mathrm{C} \mathrm{m}^{2} \mathrm{~W}^{-1}$ for greenhouse worker clothes). $F_{\mathrm{cl}}$ is the ratio of the clothed to the naked body area $\left(F_{\mathrm{cl}}=1.2\right.$ on average), and $h_{c}$ is the convective coefficient between the clothing surface and the surrounding air $\left(\mathrm{W} \mathrm{m}^{-2}{ }^{\circ} \mathrm{C}^{-1}\right)$ and is given by $[3,7,8]$ as

$$
h_{c}=\max \_ \text {of } \begin{cases}2.38\left(T_{\mathrm{cl}}-T_{d}\right)^{0.25}, & \text { free convection, } \\ 12.1 \sqrt{V}, & \text { forced convection. }\end{cases}
$$

Survey of previous studies revealed that no studies have been done to evaluate human thermal comfort and heat stress in greenhouses under arid climatic conditions. Accordingly, the objective of this study is to evaluate human comfort and heat stress levels in a greenhouse with and without evaporative cooling under hot arid conditions by (i) describing the mean thermal sensations of workers, (ii) evaluating the levels of heat stress the workers are exposed to, and (iii) determining the effects of the evaporative cooling of the greenhouse air on the heat stress and on the workers thermal sensations. Two hot sunny days were selected for the study: in one day the greenhouse was without cooling and in the other day the greenhouse was cooled by a wet pad and fans system. Several indices (i.e., WBGT, PET, UTCI, and SET ${ }^{*}$ ) were used for the evaluation.

\section{Experimental Measurements}

Two experiments were conducted in a greenhouse with a floor area of $48 \mathrm{~m}^{2}$, covered with a plastic film ( $0.2 \mathrm{~mm}$ thick), and include a wet pad and fans system for the evaporative cooling. The greenhouse was oriented in a N-S direction on the Agricultural Research and Experiment Station, Agriculture Engineering Department, King Saud University (Riyadh, Saudi Arabia; $46^{\circ} 47^{\prime} \mathrm{E}$, longitude, and $24^{\circ} 39^{\prime} \mathrm{N}$, latitude).
The measuring instruments were installed at $2 \mathrm{~m}$ above the greenhouse floor. Layout dimensions and locations of the instruments are illustrated in Figure 1. The greenhouse was mechanically ventilated using three suction fans (each of $130 \mathrm{~W}$ and $45.8 \mathrm{~m}^{3} \mathrm{~min}^{-1}$ ). The measurements were carried out during two 24-hour periods (each period from 6 am to 6 am in the next day) in hot sunny days (May 8-9, 1415,2012 ) to measure the required parameters in the greenhouse. During the first period, the greenhouse was without cooling and during the second period evaporative cooling was applied. The measured data were taken every $10 \mathrm{sec}$, averaged and recorded at every $10 \mathrm{~min}$ in a data logger (CR23X Micrologger), and then averaged at every one hour. The measured parameters were (i) dry and wet bulb temperatures $\left(T_{d}\right.$ and $\left.T_{w}\right)$ using aspirated psychrometer; the psychrometer had two type- $T$ thermocouples (copper constantan of $0.3 \mathrm{~mm}$ in diameter). The psychrometers were calibrated, and the error was $\leq 1.2 \%{ }^{\circ} \mathrm{C}$ for a dry bulb temperature up to $100^{\circ} \mathrm{C}$; (ii) globe temperature $\left(T_{g}\right)$ using black globe thermometric probe (BST131) having a globe diameter of $0.15 \mathrm{~m}$, a time response of $20 \mathrm{~min}$, surface reflectance $\leq 2 \%$, a working temperature range of $-50^{\circ} \mathrm{C}$ to $80^{\circ} \mathrm{C}$, and a measuring error of $\pm 0.5 \%{ }^{\circ} \mathrm{C}$ for a dry bulb temperature up to $80^{\circ} \mathrm{C}$, (iii) natural wet bulb temperature $\left(T_{\mathrm{nw}}\right)$ using a type- $T$ copper constantan thermocouple of $0.3 \mathrm{~mm}$ in diameter, whose junction was covered with a moist, white muslin wick and kept exposed to the greenhouse environment; (iv) global solar radiation flux inside the greenhouse $\left(S_{i}, \mathrm{~W} \mathrm{~m}^{-2}\right)$ using CMP3 Pyranometer (Kipp \& Zonen B.V. Inc., USA), having a maximum error of $\pm 2 \%$, a working temperature range of $-40^{\circ} \mathrm{C}$ to $+80^{\circ} \mathrm{C}$, and a wavelength range of $310-2800 \mathrm{~nm}$. The average air speed in the greenhouse was estimated, based on the greenhouse vertical cross-section area and the flow rate of air in the greenhouse, to be around $0.3 \mathrm{~m} \mathrm{~s}^{-1}$. RH was calculated by substituting the measured values of $T_{d}$ and $T_{w}$ in psychrometric relations reported in [24].

\section{Results and Discussion}

In the arid environment, existing high air temperature $\left(T_{d}\right)$, low relative humidity $(\mathrm{RH})$, and intensive solar radiation flux $\left(S_{i}\right)$ in the greenhouses (Figure 2(a)) make use of evaporative cooling which is an essential requirement to grow crops and to protect workers from heat stress risks. At around noon, the evaporative cooling of the inside greenhouse air reduced the daily maximum hourly value of $T_{d}$ by about $7 \sim 8^{\circ} \mathrm{C}$ and enhanced the daily minimum hourly value of RH by about 20 25\% (Figures 2(a) and 2(b)). In the present study, the effectiveness of the cooling system was low because the pad was old and partially blocked with salts on the pad surfaces (the cooling water used was brackish). Therefore, the reduction in $T_{d}$ and the increase in $\mathrm{RH}$ were relatively low compared to the optimum environment for crop growth to be achieved $\left(20-30^{\circ} \mathrm{C} T_{d}\right.$ and $\left.70-80 \% \mathrm{RH}\right)$. A slight reduction in $S_{i}$ may occur due to the effect of water vapor that is attenuates and/or absorbs the transmitted solar radiation into the greenhouse. It is worth mentioning that the current experiments were conducted in two different days, with each having its 


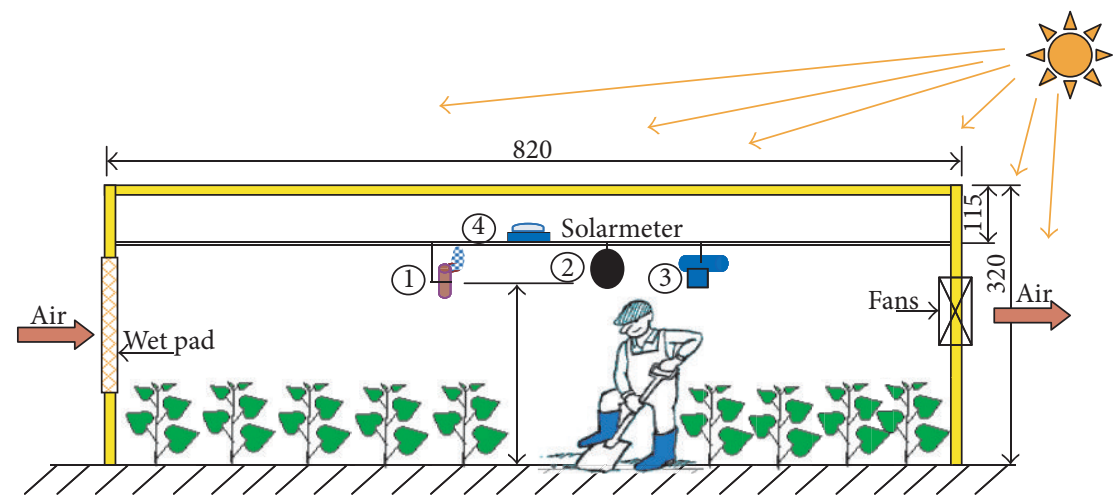

(1) Thermocouple junction to measure the natural wet bulb temperature $\left(T_{\mathrm{nW}}\right)$

(2) Black glob sensor to measure $T_{g}$

(3) Aspirated psychrometer to measure dry and wet bulb temperature $\left(T_{d}, T_{w}\right)$

(4) Pyranometer to measure solar radiation flux

FIGURE 1: Layout dimensions (in $\mathrm{cm}$ ) and locations of the instruments used to measure the required environmental parameters in the greenhouse.

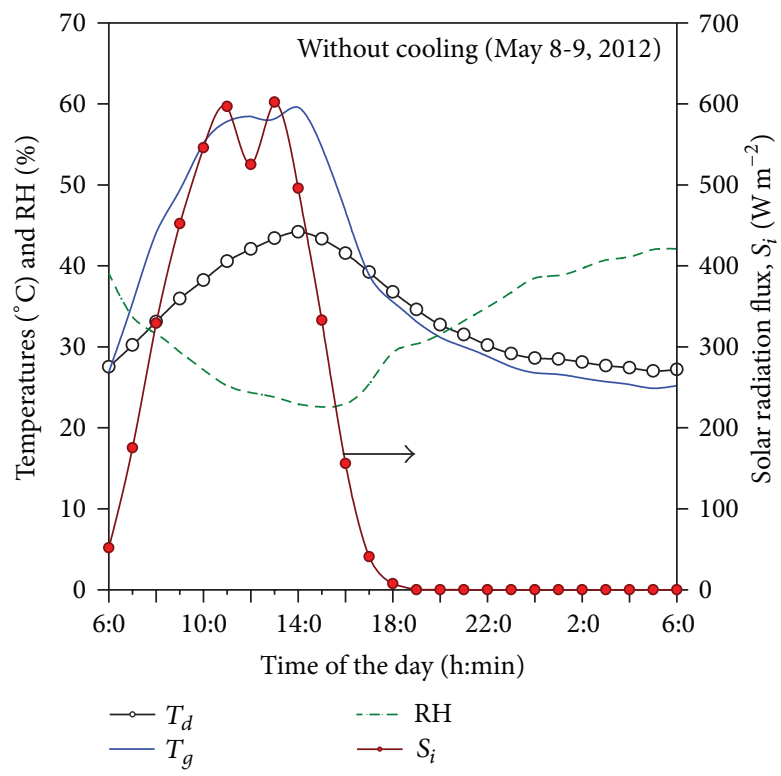

(a)

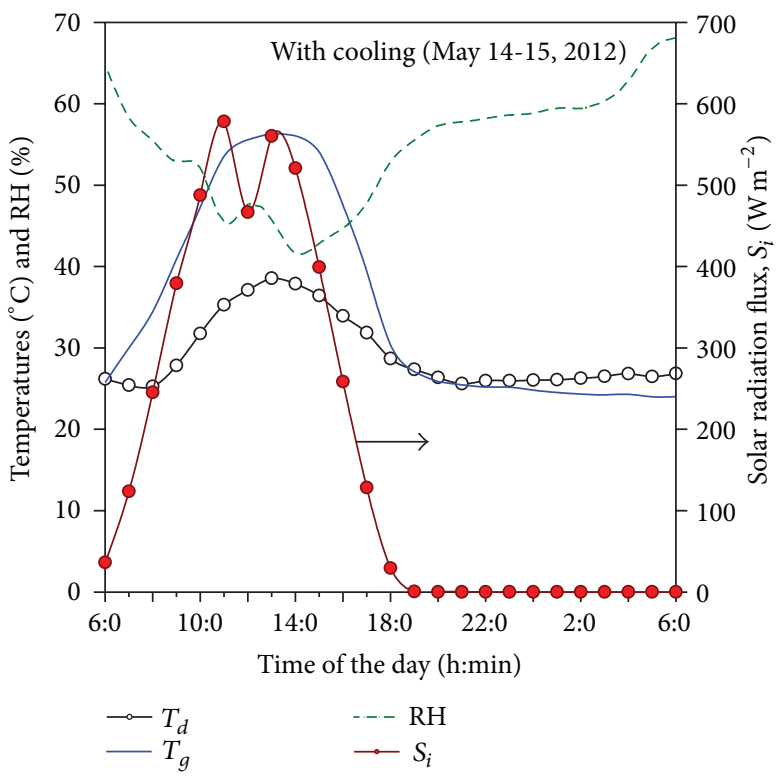

(b)

Figure 2: Time course of the dry bulb temperature $\left(T_{d}\right)$, relative humidity $(\mathrm{RH})$, and solar radiation flux $\left(S_{i}\right)$ measured in the greenhouse: (a) without cooling and (b) with cooling of the inside air.

own $T_{d}$ and $\mathrm{RH}$ distributions along with the day. Therefore, it is difficult to show the exact effects of the evaporative cooling on $T_{d}, \mathrm{RH}, S_{i}$, and on the other parameters as well. To show the exact effect, two identical greenhouses are needed, one is without cooling, and the other with cooling and should be operated on time at the same location.

The values of $T_{\text {mrt }}$ (Figures 3(a) and 3(b)), PE, and SET ${ }^{*}$ in degree ${ }^{\circ} \mathrm{C}$ were calculated by using RayMan software model. The input parameters were the values of $T_{d}, \mathrm{RH}$, and $S_{i}$ in addition to the body input parameters (i.e., human activity, $M$ value; clothing factor, 0.6 clo; gender, man; height, $175 \mathrm{~cm}$; and weight, $75 \mathrm{~kg}$ ). The main source of discomfort and heat stress in the greenhouses is the heat load exchanges between the workers and their surroundings through radiation and convection modes. Radiation exchange depends on the difference, to the power four, between the mean radiant temperature $\left(T_{\mathrm{mrt}}\right)$ and clothing surface temperature $\left(T_{\mathrm{cl}}\right)$; the convection exchange depends on the difference between $T_{\mathrm{cl}}$ and $T_{d}$. The time courses of the $T_{\mathrm{mrt}}, T_{\mathrm{cl}}$ (predicted by using (2)), and $T_{d}$ are illustrated in Figures 3(a) and 3(b) in the greenhouse without and with cooling, respectively. Evaporative cooling reduces $T_{\mathrm{mrt}}, T_{\mathrm{cl}}$, and $T_{d}$ and consequently modifies the environment in the greenhouse. This figure shows that, during the day time, $T_{\text {mrt }}$ was much higher than 


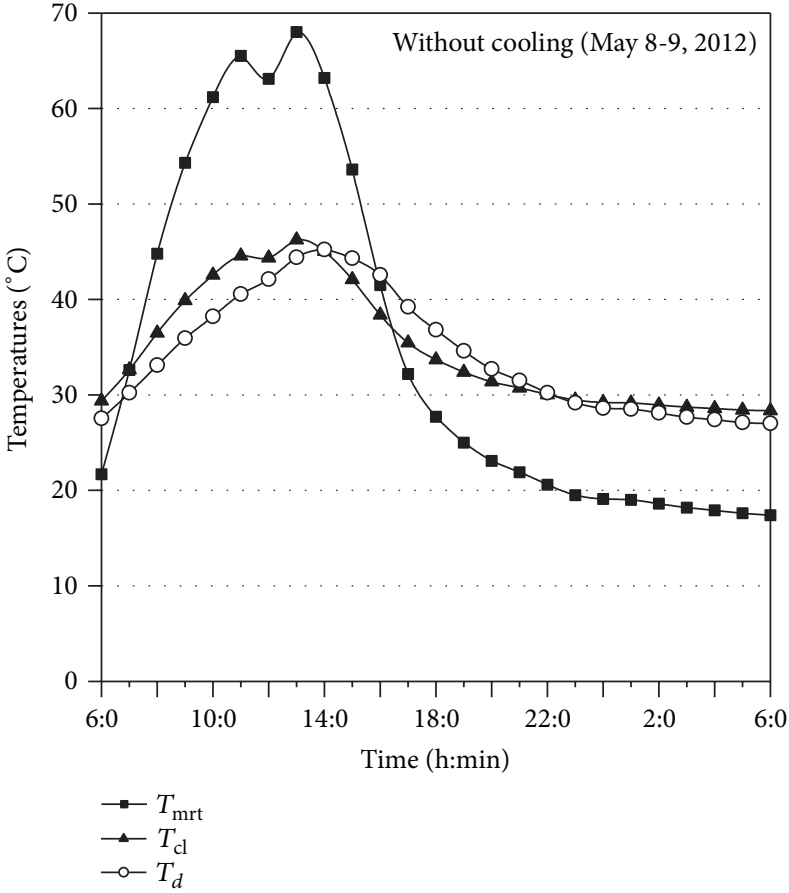

(a)

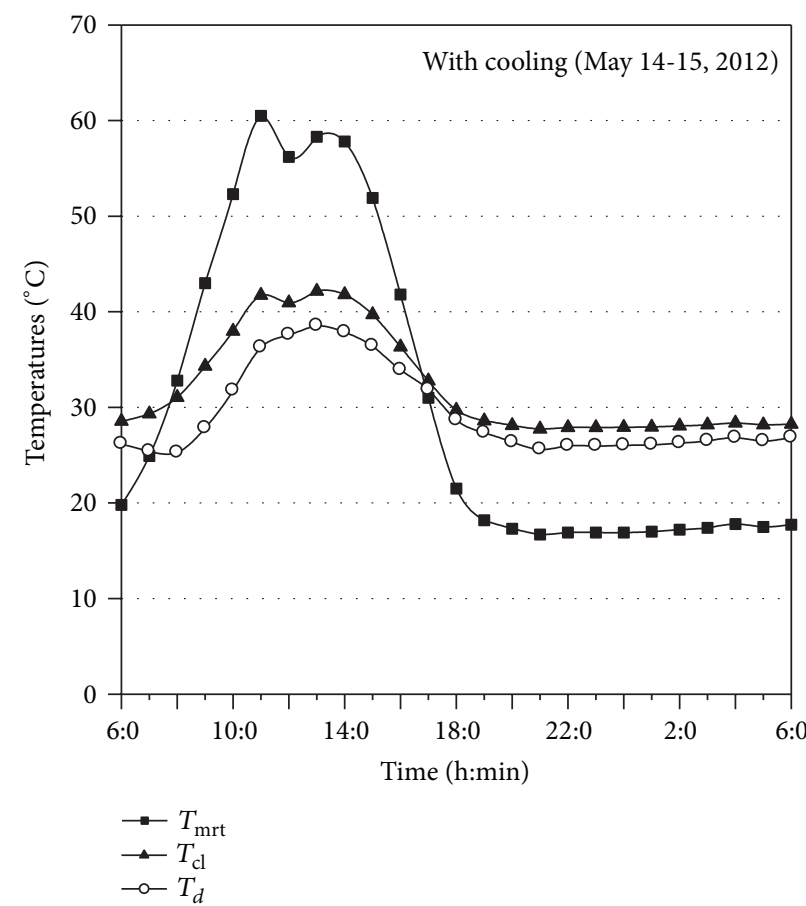

(b)

FIgURE 3: Time course of the mean riant temperature $\left(T_{\mathrm{mrt}}\right)$, clothing temperature $\left(T_{\mathrm{cl}}\right)$, and dry bulb temperature $\left(T_{d}\right)$ estimated in the greenhouse: (a) without cooling and (b) with cooling of the inside air.

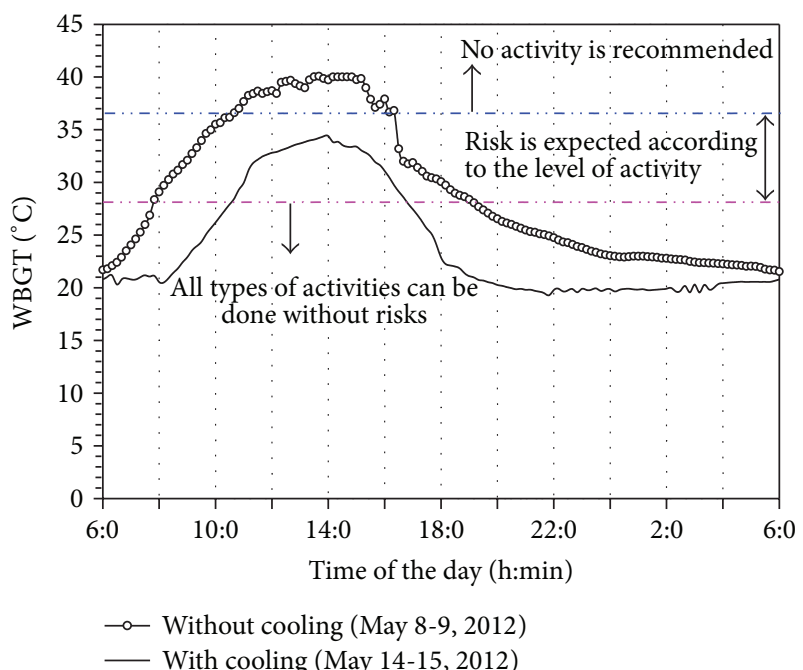

Figure 4: Time course of the wet bulb globe temperature index (WBGT) estimated in the greenhouse with and without cooling of the inside air.

$T_{\mathrm{cl}}$. Therefore, worker's body always experiences a positive heat radiation load (i.e., heat gain). During the night time, $T_{\mathrm{mrt}}$ was lower than $T_{\mathrm{cl}}$ causing a negative radiation heat load (released from the body). The convection exchange is minor during the day and night times. However, radiation heat load has the dominant effect because the temperature difference $\left(T_{\mathrm{mrt}}-T_{\mathrm{cl}}\right)$ is much higher than $\left(T_{d}-T_{\mathrm{cl}}\right)$.

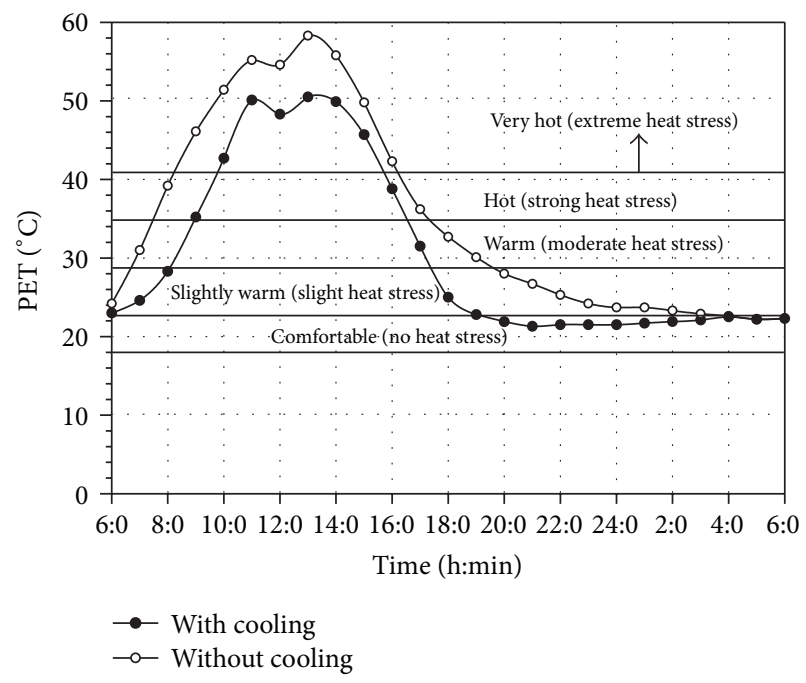

FIGURE 5: Time course of the physiological effective temperature (PET) estimated in the greenhouse with and without cooling of the inside air.

Equation (1) is used to estimate the WBGT based on the measured values of $T_{d}, T_{g}$, and $T_{\mathrm{nw}}$. Figure 4 illustrates the time course of the WBGT during 24-hour period in the greenhouse with and without cooling. The evaporative cooling significantly reduces the WBGT and the heat stress as well and consequently improves the comfort conditions of workers. According to the predicted values of the WBGT 


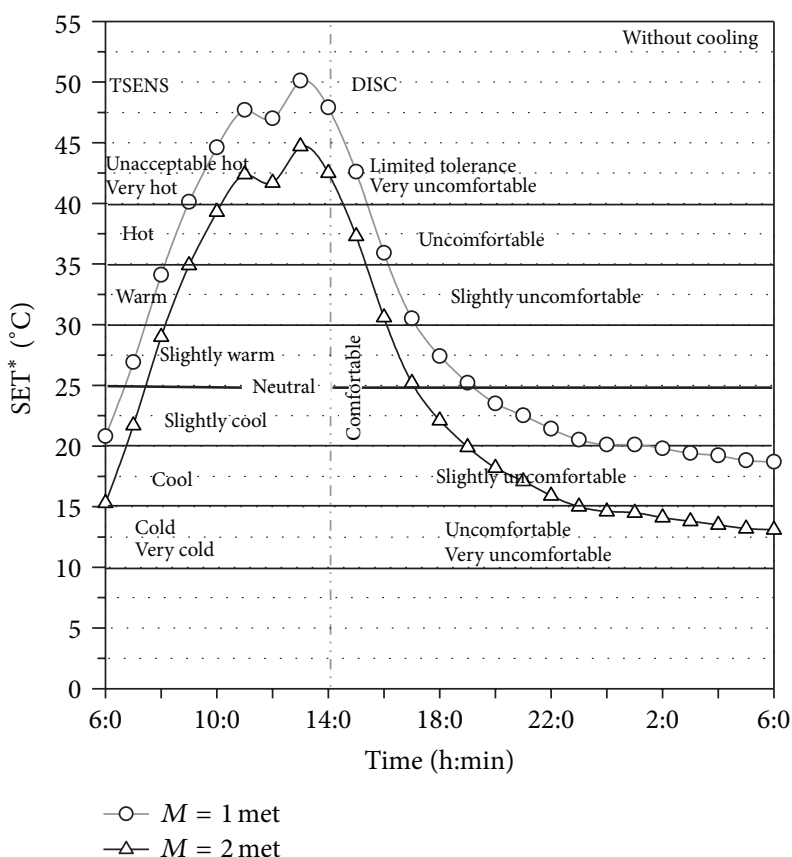

(a)

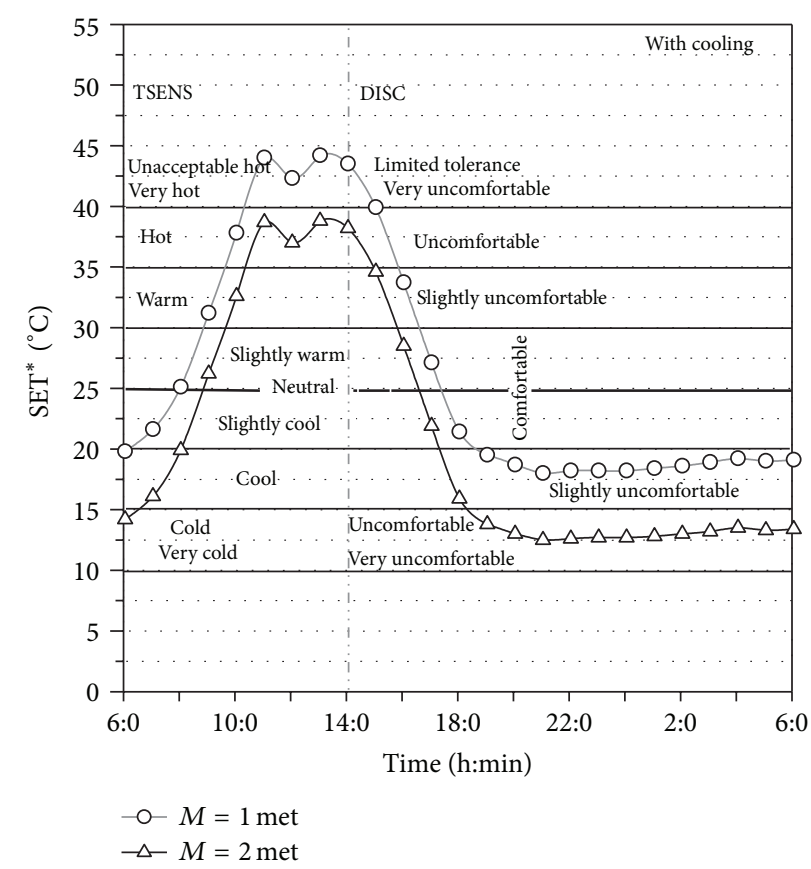

(b)

FIGURE 6: Time course of the standard effective temperature $\left(\mathrm{SET}^{*}\right)$ estimated in the greenhouse: (a) without cooling and (b) with cooling of the inside air.

in the cooled greenhouse, several types of activities can be done safely along the day and night times. However, the level of activity (light, medium, or heavy) and the work-rest time should be scheduled along the daytime according to the permissible value of the WBGT to avoid risks of thermal stresses and discomfort sensation. A classification of different levels of activity that can be done and the corresponding highest permissible value of the WBGT is illustrated in Table 1. Workers following these instructions (Table 1) will be safe in the greenhouse in hot arid climate.

Figure 5 illustrates the time course of the PET $\left({ }^{\circ} \mathrm{C}\right)$ indicating the mean sensations of workers and the corresponding level of heat stress during 24-hour period in the greenhouse with and without cooling of the inside air. Efficient evaporative cooling is expected to reduce the heat stress level and improve the comfort conditions of workers. However, in this study workers would feel very hot and exposed to very strong heat stress during most of the day $(10 \mathrm{am}-3: 30 \mathrm{pm})$ because the cooling system operated at low efficiency. During the rest of the day, the mean sensations are distributed on the figure as slightly warm, warm, and hot. Workers would feel comfortable during the night time and slightly warm in the morning and in the afternoon.

The SET* index was calculated by RayMan software model based on the hourly estimated values of $T_{d}, \mathrm{RH}$, and $S_{i}$ in the greenhouse, without and with cooling of the inside air, and as illustrated in Figures 6(a) and 6(b), respectively. Unlike the PET and UTCI indices, the SET ${ }^{*}$ depends of the level of activity (met value). Accordingly, the time course of the SET ${ }^{*}$ is estimated in the greenhouse for two levels of activities ( $M=1$ and $2 \mathrm{met}$ ). The thermal sensation (TSENS)

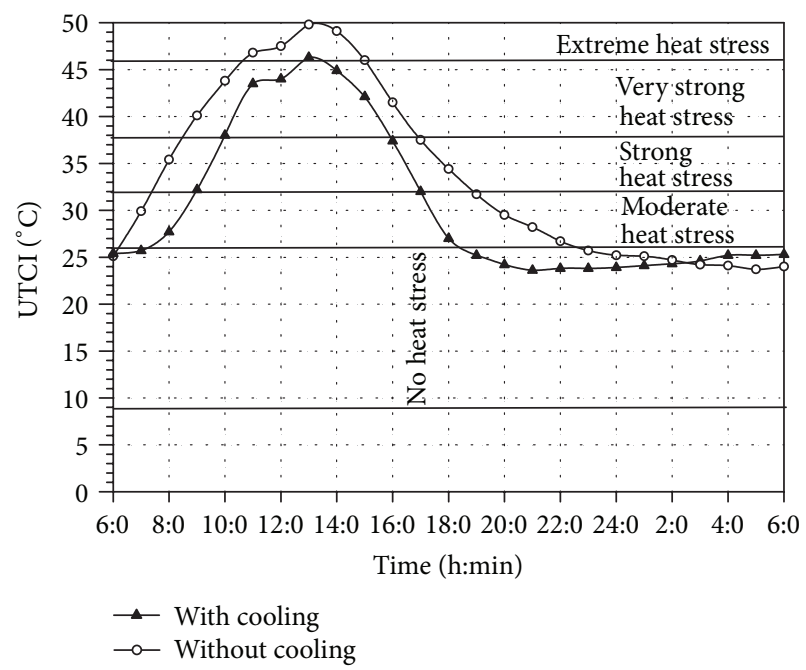

FIgURE 7: Time course of the universal thermal climatic index (UTCI) estimated in the greenhouse with and without cooling of the inside air.

and the discomfort conditions (DISC) were also illustrated in Figures 6(a) and 6(b). Values of SET ${ }^{*}$ give more details for the distribution of thermal sensation and discomfort conditions along the day and night times. Apart from the cooling effect, slight increase in the level of activity (from 1 to 2 met) improves the comfort conditions during the daytime. In the cooled greenhouse, workers would feel uncomfortable at around noon and during the night times. The evaporative 


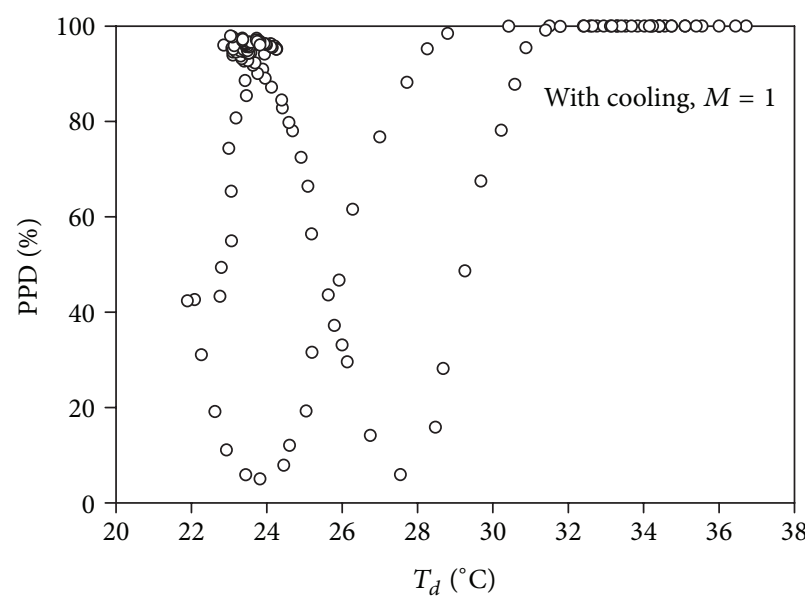

(a)

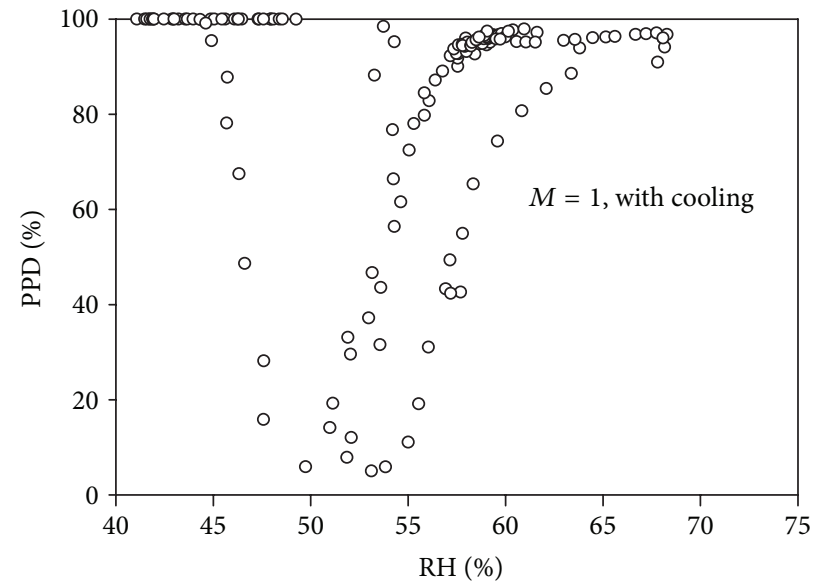

(b)

FIGURE 8: The dry bulb temperature $\left(T_{d}\right)$ and relative humidity $(\mathrm{RH})$ against the predicted percentage of dissatisfied (PPD) estimated at low or no activity $(M=1)$ in the cooled greenhouse: (a) for $T_{d}$ and (b) for RH.

cooling slightly reduces the heat stress level and improves the comfort conditions during the day time. However, using the evaporative cooling during the night time is not necessary. An efficient cooling to the greenhouse air should be performed during the day time to achieve better thermal sensation and to avoid heat stress risks.

The time course of the universal thermal climatic index (UTCI) is illustrated in Figure 7. This index was estimated in the greenhouse during 24-hour period with and without cooling of the inside air. The UTCI calculator $[21,22]$ was used, and the hourly estimated values of $T_{d}, \mathrm{RH}$, and the temperature difference $\left(T_{\mathrm{mrt}}-T_{d}\right)$ were the input parameters to the calculator. Based on the UTCI values in Figure 7, the time period at which a certain level of heat stress occurred (periods of slight, moderate, strong, and very strong) is almost similar to those in Figure 5. Accordingly, either PET or UTCI (i.e., heat stress scales) can be used to describe heat stress levels in the greenhouses along the day under arid conditions. However, SET ${ }^{*}$ is a thermal comfort scale provides more specific information about thermal sensation (TSENS) and discomfort conditions (DISC) along the day and night times.

In the cooled greenhouse, using the predictive mean vote index (PMV) with its limited scale $(-3$ to +3$)$ is possible to evaluate the comfort conditions. Value of the PMV was calculated by using RayMan software model as PET and SET $^{*}$ scales. Thus, the percent of workers who likely feel uncomfortable (i.e., the predicted percentage of dissatisfied, PPD\%) can be calculated according to [3] as PPD $=100-$ $95 \operatorname{Exp}\left(-0.03353 \mathrm{PMV}^{4}-0.2179 \mathrm{PMV}^{2}\right)$. Values of the PPD was estimated for the cooled greenhouse and plotted against $T_{d}$ in Figure 8(a) and against RH in Figure 8(b), respectively. The results of this figure showed that the lowest value of the PPD was about $5 \%$ when $T_{d}$ was in the range of $24-28^{\circ} \mathrm{C}$ (Figure $8(\mathrm{a})$ ) and when $\mathrm{RH}$ was in the range of $48-55 \%$ (Figure $8(\mathrm{~b})$ ). This means that about $95 \%$ of the greenhouse workers would be satisfied with the surrounding environment under such conditions. These results are in accordance with the standard comfort conditions (i.e., PPD < $5 \%$ when $T_{d}=25^{\circ} \mathrm{C}$ and $\left.\mathrm{RH}=50 \%\right)$ [3]. Lowering $T_{d}$ to be less than $24^{\circ} \mathrm{C}$ and $\mathrm{RH}$ less than $48 \%$ will produce cooled feeling and cold stress; and increasing $T_{d}$ to be more than $28^{\circ} \mathrm{C}$ and $\mathrm{RH}$ more than $55 \%$ will produce hot feeling and thermal stress. However, in most cases these ranges of $\mathrm{RH}$ and $T_{d}$ are not exactly suitable for plant growth requirements, and this is another challenge should be taken into consideration.

\section{Conclusion and Recommendation}

Human thermal comfort and heat stress in a greenhouse in summer under arid climatic conditions were evaluated. Effect of the evaporative cooling of the greenhouse air on the heat stress and on the comfort conditions of workers was also examined. The main conclusions from this study could be summarized as follows.

(i) In the uncooled greenhouses, workers would feel very hot and uncomfortable most of the day time, especially at around noon; the heat stress risk is expected. However, workers are safe from heat stress and would fell comfort most of the night time.

(ii) Efficient evaporative cooling of the greenhouse air can improve the comfort conditions of workers and reduce the heat stress levels during the hot sunny days in arid climate. Cooling the greenhouse air should be applied during the day time in summer. However, during the night times, cooling is not necessary.

(iii) In the cooled greenhouses, the activities of workers should be scheduled and distributed along the day according to the highest permissible values of the WBGT.

(iv) The PET or the UTCI scale can be used to evaluate heat stress potential in the greenhouses under arid 
conditions. The $\mathrm{SET}^{*}$ is an optimum scale to specifically describe the thermal sensations and discomfort conditions along the day in the greenhouses at any level of activity.

(v) A relative humidity in the range of $48-55 \%$ and a dry bulb temperature in the range of $24-28^{\circ} \mathrm{C}$ in the greenhouses can provide comfort sensation to around $95 \%$ of the greenhouse workers in arid climate.

\section{Nomenclatures}

$h_{c}$ : Convective coefficient between the clothing surface and the surrounding ( $\mathrm{W} \mathrm{m}^{-2}{ }^{\circ} \mathrm{C}^{-1}$ )

$I_{\mathrm{cl}}$ : Insulation factor of the entire clothing $\left(\mathrm{W}^{\circ} \mathrm{C} \mathrm{m}^{-2}\right)$

M: Metabolic heat generation rate (met, $1 \mathrm{met}=58.15 \mathrm{~W} \mathrm{~m}^{-2}$ )

$\mathrm{RH}$ : Relative humidity of the greenhouse air (\%)

$T_{d}$ : Dry bulb temperature of the greenhouse air $\left({ }^{\circ} \mathrm{C}\right)$

$T_{\mathrm{cl}}$ : Clothing surface temperature $\left({ }^{\circ} \mathrm{C}\right)$

$T_{g}$ : Globe temperature $\left({ }^{\circ} \mathrm{C}\right)$

$T_{\mathrm{nw}}$ : Natural wet bulb temperature of the greenhouse air $\left({ }^{\circ} \mathrm{C}\right)$

$T_{w}$ : Wet bulb temperature of the greenhouse air $\left({ }^{\circ} \mathrm{C}\right)$

$T_{\text {mrt }}$ : Mean radiant temperature in the greenhouse $\left({ }^{\circ} \mathrm{C}\right)$

$W$ : External mechanical work done by the worker $\left(\mathrm{W} \mathrm{m}^{-2}\right)$.

\section{Abbreviations of Thermal Scales}

PET: $\quad$ Physiological effective temperature $\left({ }^{\circ} \mathrm{C}\right)$

PMV: $\quad$ Predictive mean vote scale $(-)$

PPD: $\quad$ Predicted percentage of dissatisfied (\%)

SET $^{*}$ : $\quad$ Standard effective temperature $\left({ }^{\circ} \mathrm{C}\right)$

UTCI: Universal thermal climatic index $\left({ }^{\circ} \mathrm{C}\right)$

WBGT: Wet bulb globe temperature $\left({ }^{\circ} \mathrm{C}\right)$.

\section{Acknowledgment}

This work was supported by the National Plan for Sciences and Technology (NPST) Program, King Saud University as a research project No. 09-ADV914-02.

\section{References}

[1] L. Okushima, S. Sase, L. In-Bok, and B. J. Bailey, "Thermal environment and stress of workers in naturally ventilated greenhouses under mild climate," in Proceedings of the 5th International Symposium on Protected Cultivation in Mild Winter Climates: Current Trends for Suistainable Technologies, Fernandez, Martinez, and Castilla, Eds., pp. 793-798, 2001.
2] T. Shimazu, H. Hamamoto, T. Okada, T. Ikeda, and K. Tanaka, "Microclimate and human thermal comfort in pipe greenhouses with insect-proof screens for vegetable cultivation with restricted use of chemical pesticides," Journal of Agricultural Meteorology of Japan, vol. 60, no. 5, pp. 813-816, 2005.

[3] "Thermal environmental conditions for human occupancy," ANSI/ASHRAE Standard 55, The American Society of Heating, Refrigeration and Air Conditioning Engineers, Atlanta, Ga, USA, 2004.

[4] B. Givoni, M. Noguchi, H. Saaroni et al., "Outdoor comfort research issues," Energy and Buildings, vol. 35, no. 1, pp. 77-86, 2003.

[5] S. Atthajariyakul and T. Leephakpreeda, "Neural computing thermal comfort index for HVAC systems," Energy Conversion and Management, vol. 46, no. 15-16, pp. 2553-2565, 2005.

[6] A. Forsthoff and H. Neffgen, "The assessment of heat radiation," International Journal of Industrial Ergonomics, vol. 23, no. 5-6, pp. 407-414, 1999.

[7] "Introduction to thermal comfort standard," http://www.utci org/cost/publications/ISO\%20Standards\%20Ken\%20Parsons .pdf.

[8] L. Bánhidi and Z. B. Biro, "Design and calculation possibilities for the heat exchange conditions of the human body," Periodica Polytechnica, Mechanical Engineering, vol. 44, no. 2, pp. 185-193, 2000.

[9] L. Serres, A. Trombe, and J. Miriel, "Solar fluxes absorbed by the dweller of glazed premises. Influence upon the thermal comfort equation," International Journal of Thermal Sciences, vol. 40, no. 5, pp. 478-488, 2001.

[10] M. Prek, "Thermodynamical analysis of human thermal comfort," Energy, vol. 31, no. 5, pp. 732-743, 2006.

[11] S. Yilmaz, S. Toy, and H. Yilmaz, "Human thermal comfort over three different land surfaces during summer in the city of Erzurum, Turkey," Atmosfera, vol. 20, no. 3, pp. 289-297, 2007.

[12] H. Mayer, J. Holst, and F. Imbery, "Human thermal comfort within urban structures in a central European city", in Proceeding of the 7th International Conference on Urban Climate, Yokohama, Japan, June2009.

[13] Y. Epstein and D. S. Moran, "Thermal comfort and the heat stress indices," Industrial Health, vol. 44, no. 3, pp. 388-398, 2006.

[14] C. Deb and A. Ramachandraiah, "Review of studies on outdoor thermal comfort using physiological equivalent temperature (PET)," International Journal of Engineering Science and Technology, vol. 92, no. 7, pp. 2825-2828, 2011.

[15] S. Thorsson, F. Lindberg, I. Eliasson, and B. Holmer, "Different methods for estimating the mean radiant temperature in an outdoor urban setting," International Journal of Climatology, vol. 27, no. 14, pp. 1983-1993, 2007.

[16] "Estimating wet bulb globe temperature using standard meteorological Measurements," WSRC-MS-99-00757, http://sti.srs .gov/fulltext/ms9900757/ms9900757.pdf\#search='wsrcms9900 757 .

[17] T. Itagi, "Deployment of laborsaving and comfortable technology on cultivation Management," in Handbook of Greenhouse Horticulture, JAGH, Ed., pp. 218-227, Agripress, Tokyo, Japan, 2003.

[18] A. M. Abdel-Ghany, I. M. Al-Helal, and M. R. Shady, "Human thermal comfort and heat stress in an outdoor urban arid environment: a case study," Advances in Meteorology, vol. 2013, Article ID 693541, 7 pages, 2013. 
[19] A. Matzarakis, F. Rutz, and H. Mayer, "Modelling radiation fluxes in simple and complex environments: application of the RayMan model," International Journal of Biometeorology, vol. 51, no. 4, pp. 323-334, 2007.

[20] A. Matzarakis, F. Rutz, and H. Mayer, "Modeling the thermal bioclimate in urban areas with the RayMan model," in Proceeding of the 23rd Conference on Passive and Low Energy Architecture (PLEA '06), Geneva, Switzerland, September 2006.

[21] http://www.utci.org/utci_doku.php.

[22] http://www.utci.org/utcineu/utcineu.php.

[23] "OSHA Technical Manual (OTM). Section III: chapter IV: heat stress," https://www.osha.gov/dts/osta/otm/otm_iii/otm_iii_4 .html.

[24] A. M. Abdel-Ghany, E. Goto, and T. Kozai, "Evaporation characteristics in a naturally ventilated, fog-cooled greenhouse," Renewable Energy, vol. 31, no. 14, pp. 2207-2226, 2006. 

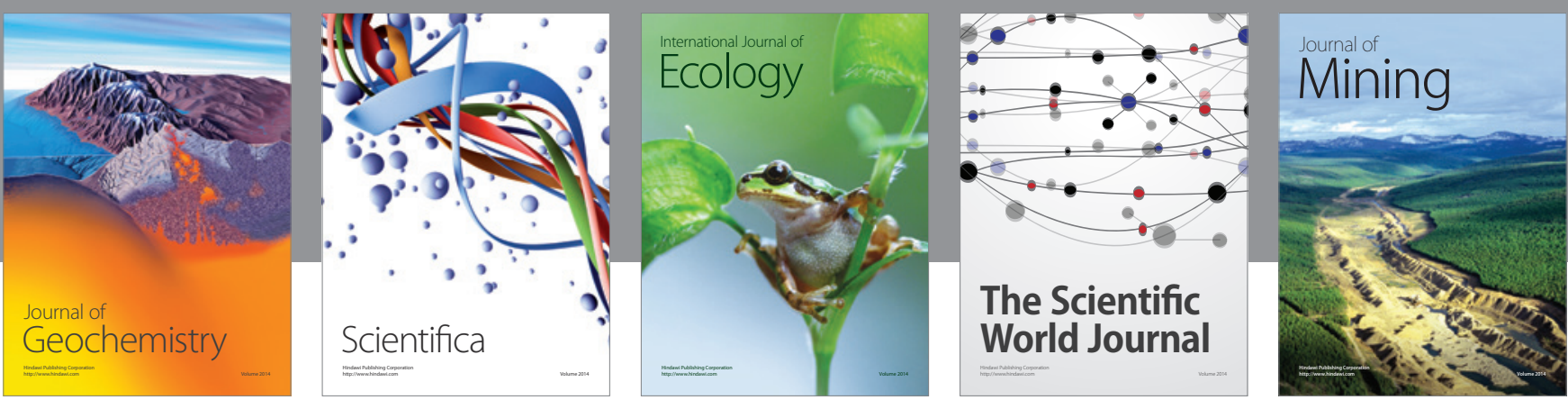

The Scientific World Journal
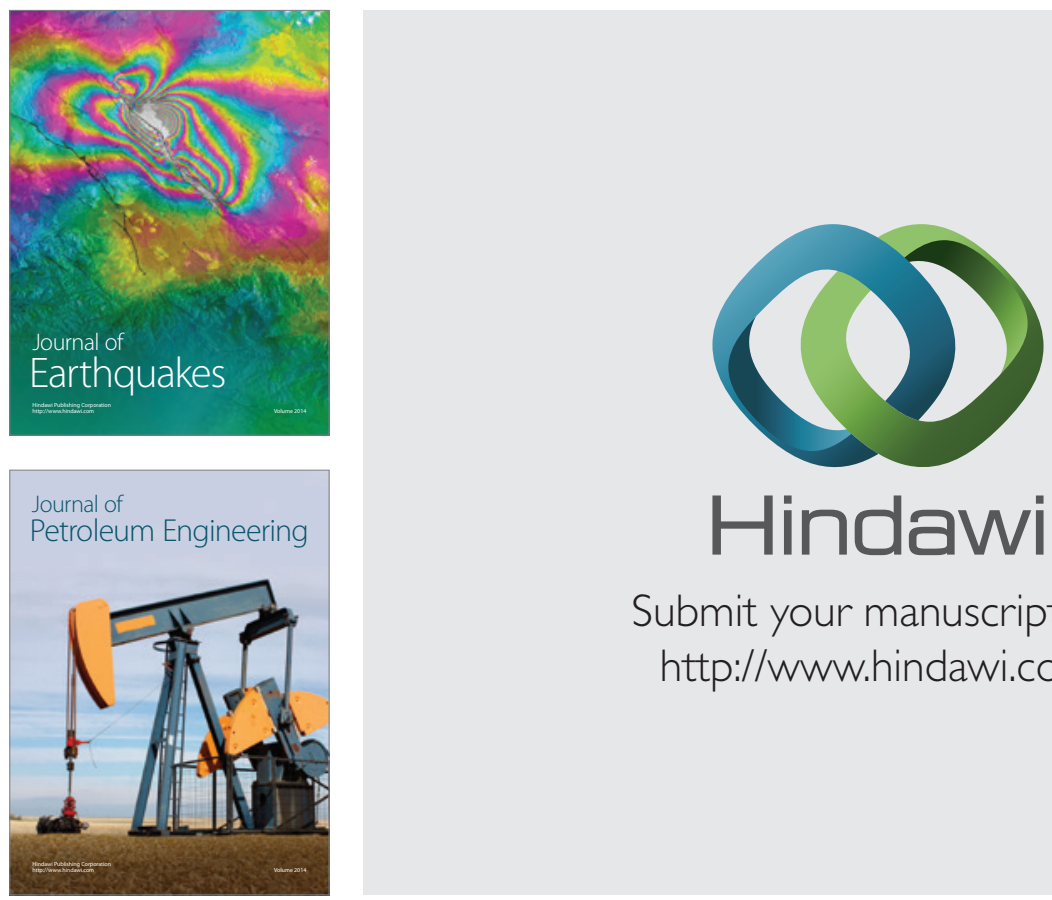

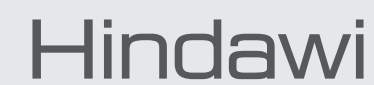

Submit your manuscripts at

http://www.hindawi.com
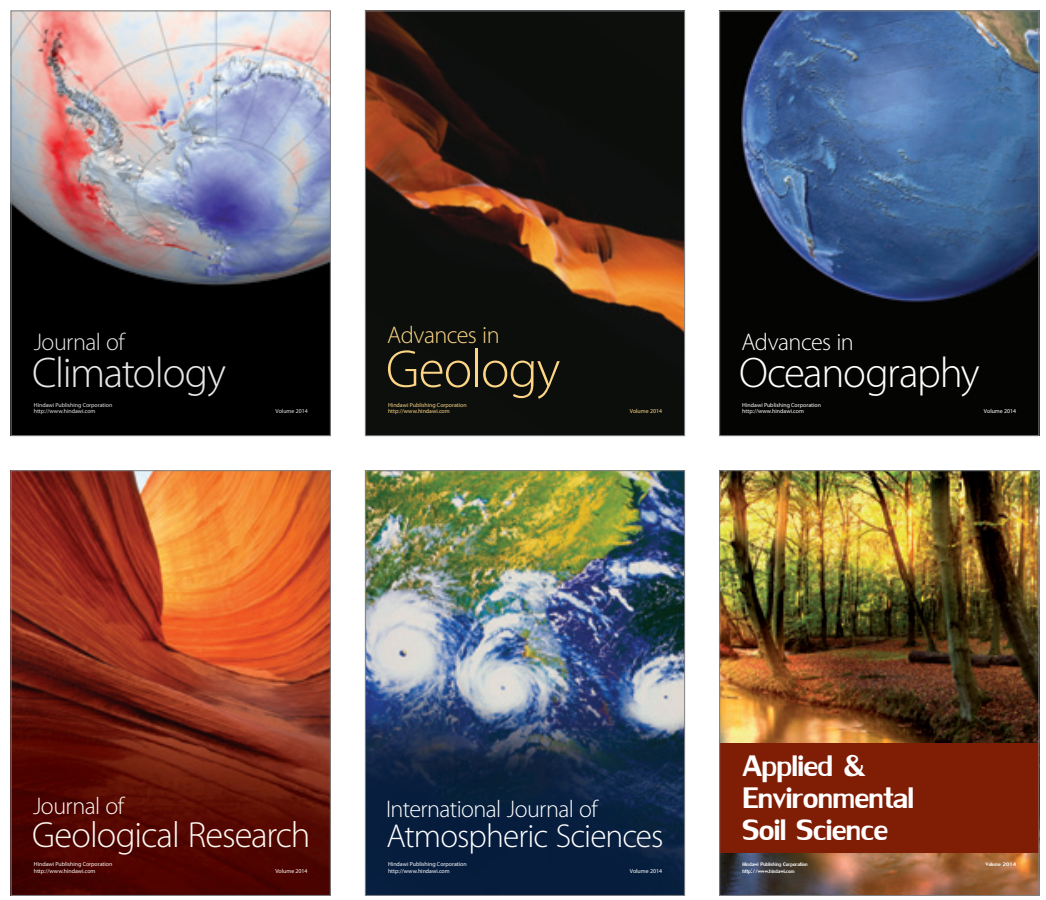
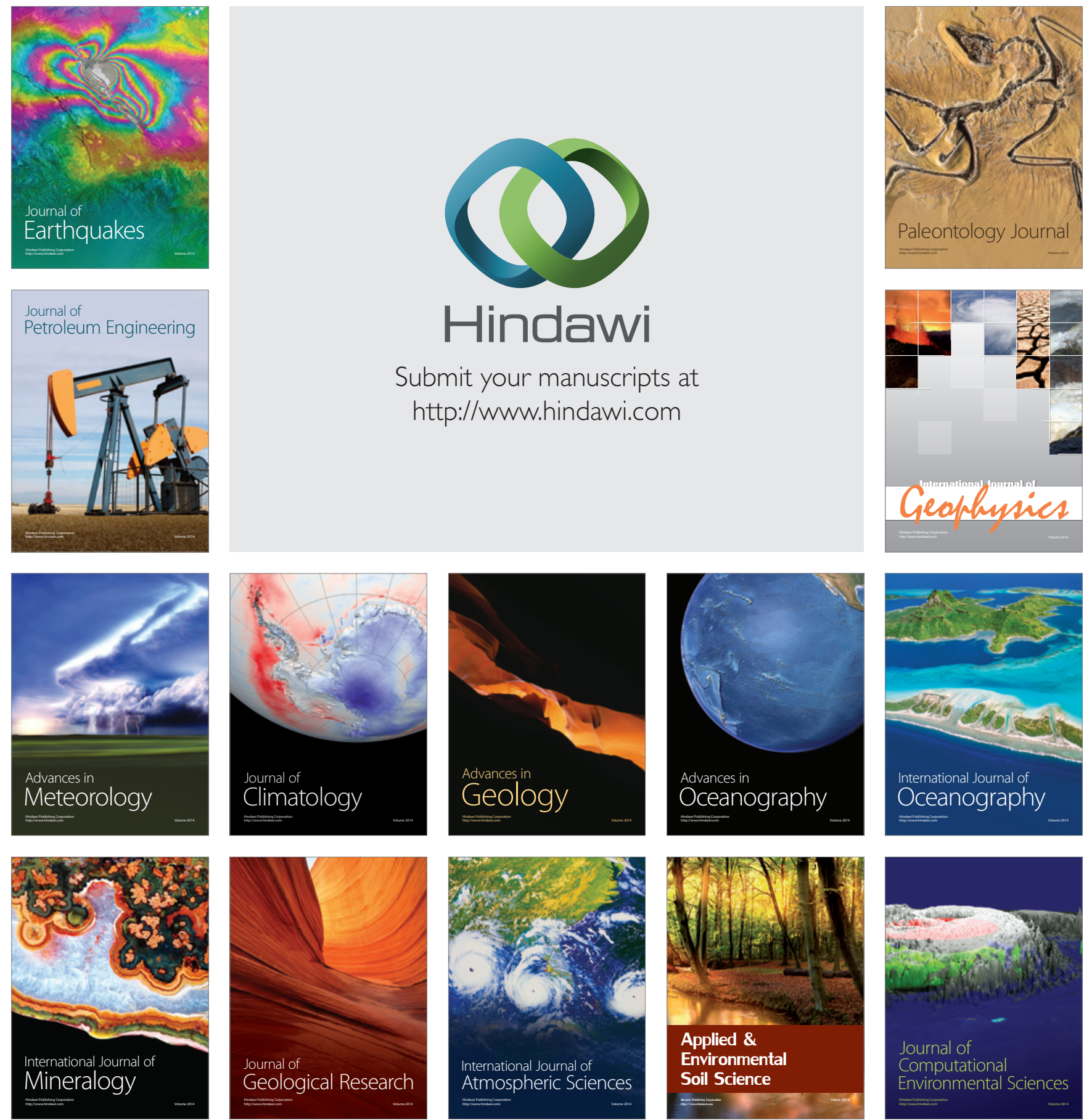